\title{
Effects of Call Arrival Rate and Mobility on Network Throughput in Multi-Cell CDMA
}

Manju Hegde, Robert Akl, Paul Min Washington University St. Louis, Missouri USA 


\section{Outline}

- CDMA Capacity and Inter-cell Effects

- Feasible Region

- Mobility Model and Blocking

- Net Revenue

- Implied Costs

- Effects of Mobility

- Maximization of Subscribers

- Maximization of Revenue

- Shaping Feasible Region 


\section{Probability of Outage}

- Single Cell

$$
\begin{aligned}
& P_{\text {out }}^{i}=\operatorname{Pr}\left(\sum_{l=2}^{n_{i}} v_{l}>\frac{(W / R)(1-\eta)}{E_{b} / I_{o}} \stackrel{\Delta}{=} K_{o}\right) \\
& \frac{I_{o}}{N_{o}}<\frac{1}{\eta} \text { where } \eta<1, \quad n_{i}: \text { users in cell } i, \\
& \operatorname{Pr}\left(v_{l}=1\right)=\alpha, \text { the voice activity factor. }
\end{aligned}
$$

\section{- Multiple Cells}

$$
P_{\text {out }}^{i}=\operatorname{Pr}\left(\sum_{l=1}^{n_{i}+\sum_{j=1}^{M} I_{j i}} v_{l}>\frac{(W / R)(1-\eta)}{E_{b} / I_{o}}\right)
$$

$M$ : total number of cells. 


\section{Probability of Outage}

$$
\begin{aligned}
& P_{\text {out }}^{i}=\operatorname{Pr}\left(\sum_{l=2}^{n_{i}} v_{l}>K_{o}\right)<\operatorname{Pr}\left(\sum_{l=1}^{n_{i}} v_{l}>K_{o}\right) \\
& \text { Let } Z_{i} \stackrel{\Delta}{=} \sum_{l=1}^{n_{i}} v_{l} \\
& \text { where } \operatorname{Pr}\left(n_{i}=k\right)=\frac{\left(\lambda_{i} / \mu_{i}\right)^{k}}{k !} e^{-\lambda_{i} / \mu_{i}}, k=0,1,2, \ldots \\
& P_{\text {out }}^{i}<\operatorname{Pr}\left(Z_{i}>K_{o}\right)=e^{-\alpha \lambda_{i} / \mu_{i}} \sum_{k=\left[K_{o}^{\prime}\right.}^{\infty}\left(\alpha \lambda \mu_{i}\right)^{k} / k !
\end{aligned}
$$




\section{Gaussian Approximation}

We approximate the Poisson by a Gaussian variable with the same mean and variance:

$$
\begin{aligned}
& P_{\text {out }}^{i} \approx Q\left(\frac{K_{o}-\mathrm{E}\left(Z_{i}\right)}{\sqrt{\operatorname{var}\left(Z_{i}\right)}}\right)=Q\left(\frac{K_{o}-\alpha \lambda_{i} / \mu_{i}}{\sqrt{\alpha \lambda_{i} / \mu_{i}}}\right) \\
& Q(y)=\int_{y}^{\infty} \frac{1}{\sqrt{2 \pi}} e^{-x^{2} / 2} d x
\end{aligned}
$$




\section{Probability of Outage for Multiple Cells}

\section{$I_{j i}$ : Inter-cell interference from cell $j$ to cell $i$.}

$$
P_{\text {out }}^{i}=\operatorname{Pr}\left(\sum_{l=1}^{n_{i}+\sum_{j=1}^{M} I_{j i}} v_{l}>\frac{(W / R)(1-\eta)}{E_{b} / I_{o}}\right)
$$

$M$ is the total number of cells. 


\section{Nine Cell Network}

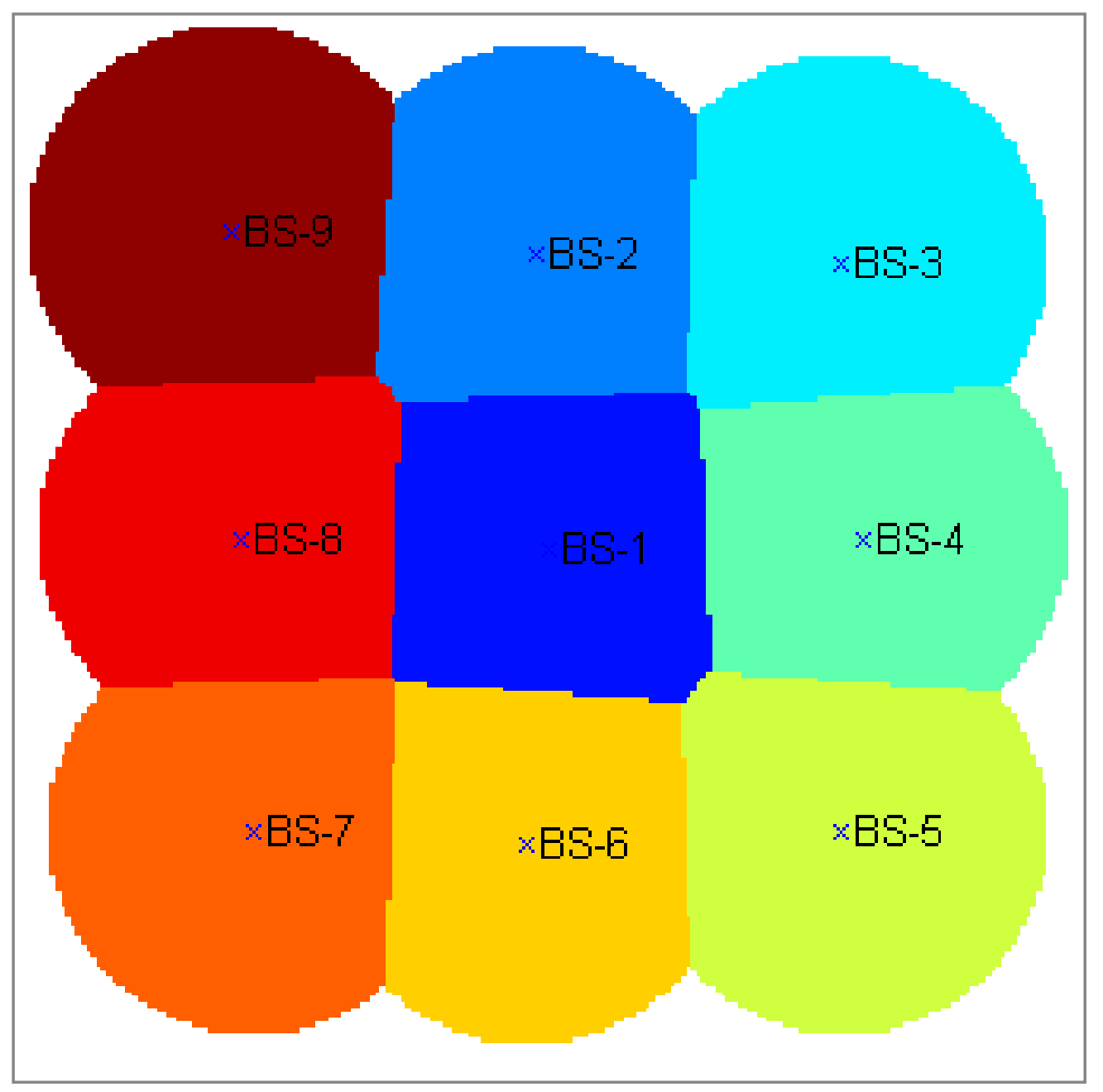




\section{Probability of Outage For Each Cell}

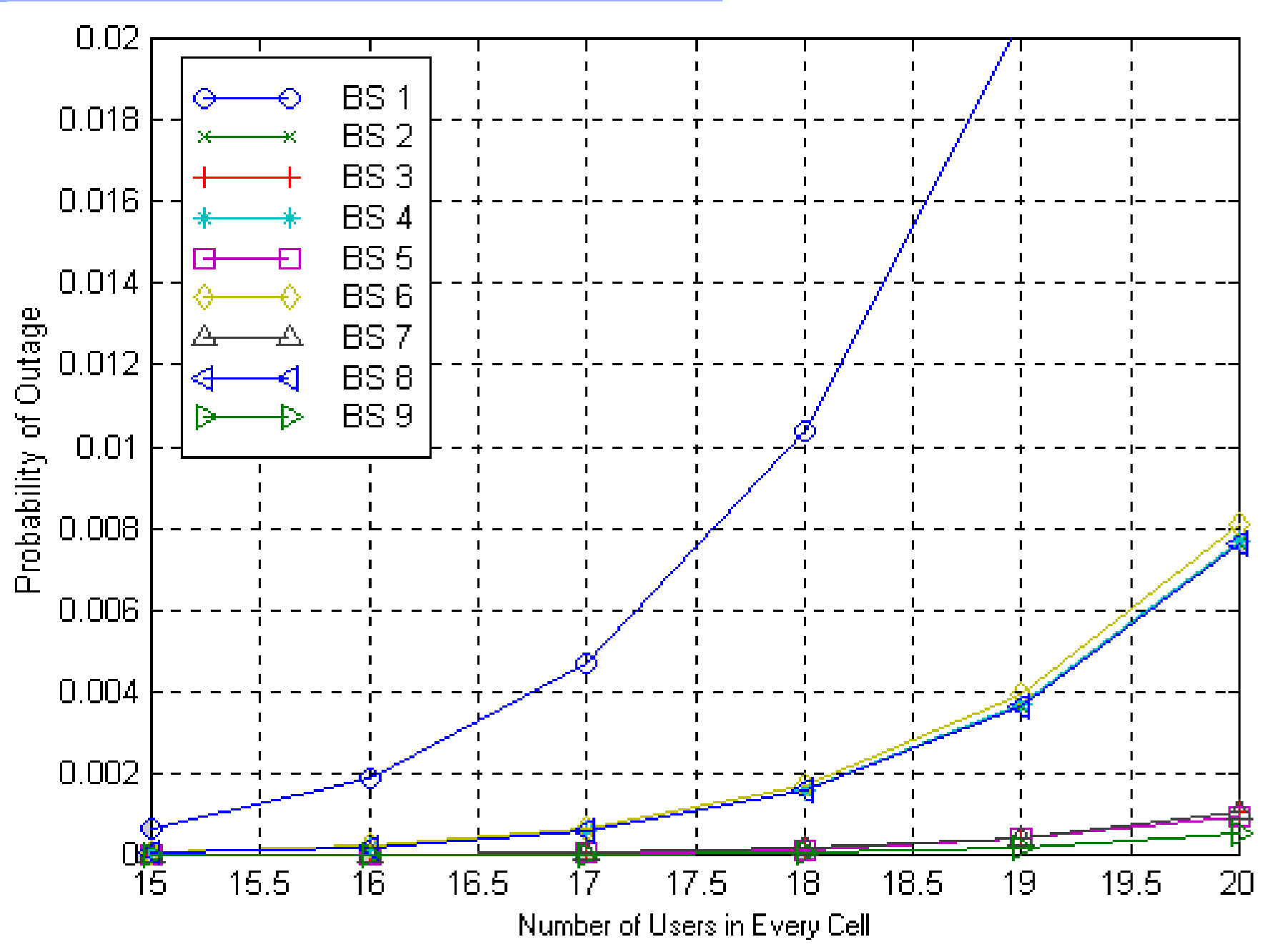




\section{Inter-Cell Interference}

$$
I_{j i}=\mathrm{E} \iint_{\text {cell } j} \frac{r_{j}^{m}(x, y) 10^{\varsigma_{j} / 10}}{r_{i}^{m}(x, y) / X_{i}^{2}} \rho_{j} d A(x, y)
$$

$m$ is the path loss exponent.

$\varsigma_{i}$ is the decibel attenuation due to shadowing, and has zero mean and standard deviation $\sigma_{s}$.

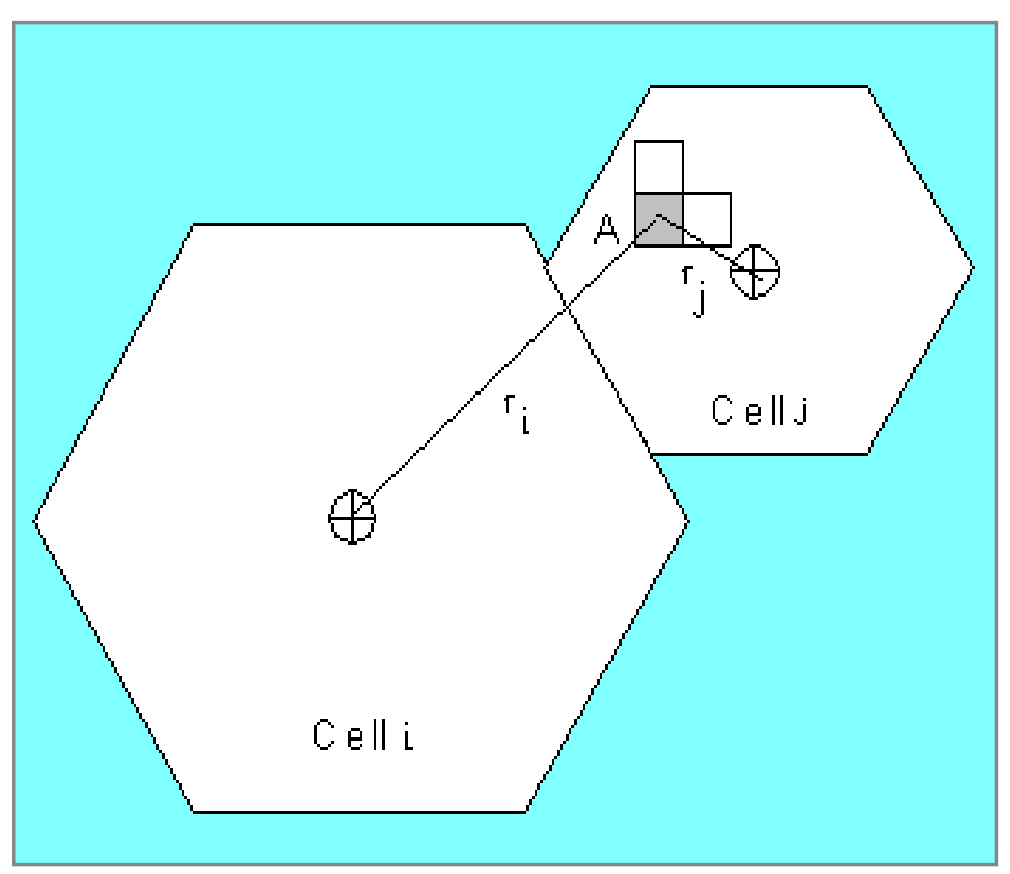
$\mathrm{E}\left[X_{i}^{2} \mid \varsigma_{i}\right]=10^{-\varsigma_{i} / 10}$

$\rho_{j}=\frac{n_{j}}{\text { Area of cell } j}$ 


\section{Soft Handoff}

User is permitted to be in soft handoff to its two nearest cells.

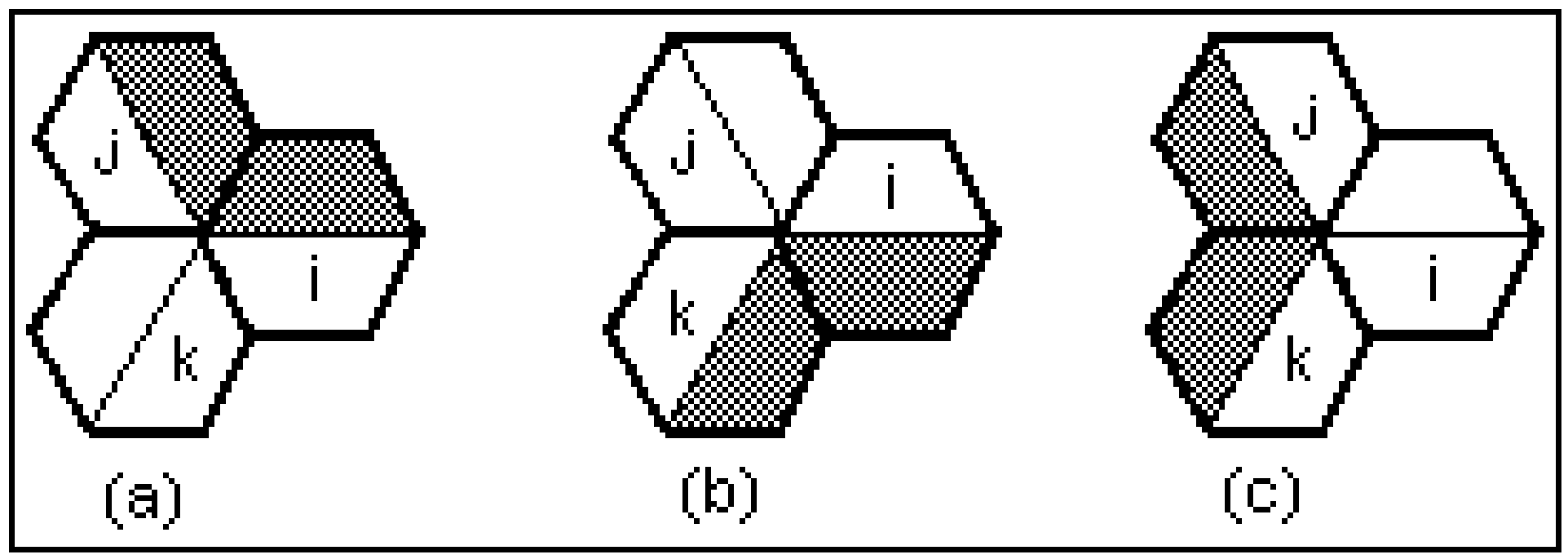




\section{Soft Handoff}

$$
\begin{aligned}
& I_{j i}=\iint_{\text {region (a) }} \frac{r_{j}^{m}}{r_{i}^{m}} \mathrm{E}\left[10^{\varsigma_{j} / 10} X_{i}^{2} \mid r_{j}^{m} 10^{\varsigma_{j} / 10}<r_{i}^{m} 10^{\varsigma_{i} / 10}\right] \rho d A(x, y) \\
& I_{k i}=\iint_{\text {region(b) }} \frac{r_{k}^{m}}{r_{i}^{m}} \mathrm{E}\left[10^{\varsigma_{k} / 10} X_{i}^{2} \mid r_{k}^{m} 10^{\varsigma_{k} / 10}<r_{i}^{m} 10^{\varsigma_{i} / 10}\right] \rho d A(x, y) \\
& I_{j i}=\iint_{\text {region(c) }} \frac{r_{j}^{m}}{r_{i}^{m}} \mathrm{E}\left[10^{\varsigma_{j} / 10} X_{i}^{2} \mid r_{j}^{m} 10^{\varsigma_{j} / 10}<r_{k}^{m} 10^{\varsigma_{k} / 10}\right] \rho d A(x, y) \\
& I_{k i}=\iint_{\text {region(c) }} \frac{r_{k}^{m}}{r_{i}^{m}} \mathrm{E}\left[10^{\varsigma_{k} / 10} X_{i}^{2} \mid r_{k}^{m} 10^{\varsigma_{k} / 10}<r_{j}^{m} 10^{\varsigma_{j} / 10}\right] \rho d A(x, y)
\end{aligned}
$$




\section{Inter-Cell Interference Factor}

- $K_{j i}$ : per user inter-cell interference factor from cell $j$ to cell $i$

- $n_{j}$ users in cell $j$ produce an amount of interference in cell $i$ equal to $n_{j} K_{j i}$ 


\section{Feasible Region}

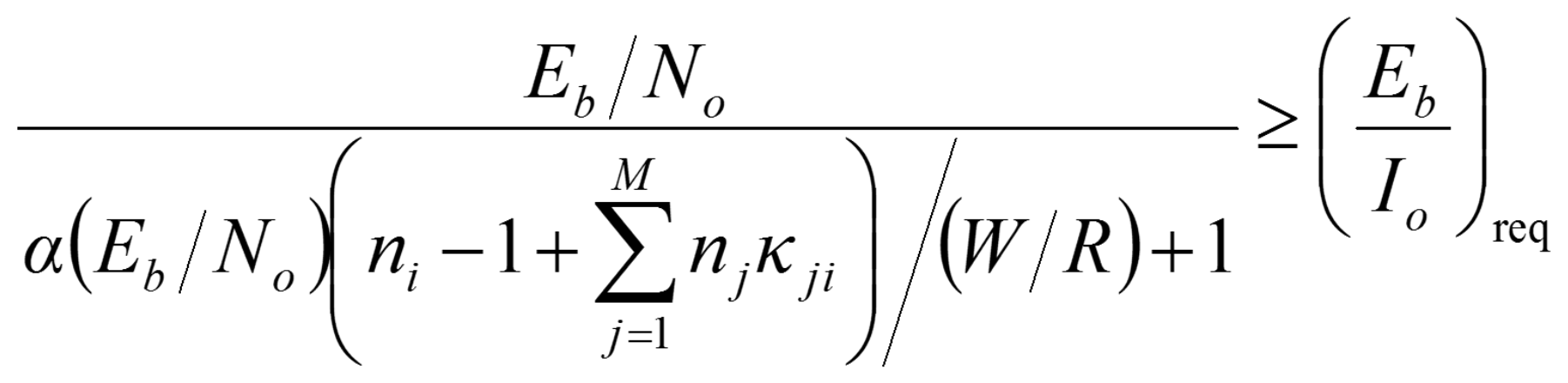

for $i=1, \ldots, M$.

$$
\begin{gathered}
n_{i}+\sum_{j=1}^{M} n_{j} \kappa_{j i} \leq \frac{W / R}{\alpha}\left(\frac{1}{E_{b} / I_{o}}-\frac{1}{E_{b} / N_{o}}\right)+1 \stackrel{\Delta}{=} c_{e f f} \\
\text { for } i=1, \ldots, M .
\end{gathered}
$$




\section{Total Offered Traffic}

- New call arrival process to cell $i$ is Poisson.

- Total offered traffic to cell $i$ is:

$\rho_{i}=\lambda_{i}+\sum_{j \in A_{i}} v_{j i}$

where $\lambda_{i}$ is the mean of the Poisson Process,

$v_{j i}$ is the handoff rate from cell $j$ to cell $i$,

$A_{i}$ is the set of cells adjacent to cell $i$. 


\section{Handoff Rate}

$$
\begin{aligned}
v_{j i} & =\lambda_{j}\left(1-B_{j}\right) q_{j i}+\left(1-B_{j}\right) q_{j i} \sum_{x \in A_{j}} v_{x j} \\
& =\left(1-B_{j}\right) q_{j i} \rho_{j}
\end{aligned}
$$

where $B_{j}$ is the Blocking probabilit y for cell $j$,

$q_{j i}$ is the probabilit y that a call in progress in cell $j$, after completing its dwell time, goes to cell $i$. 


\section{Probability of State $\underline{n}$}

$\mathrm{p}(\underline{\mathrm{n}})=\left\{\begin{array}{cc}P_{o} \prod_{k=1}^{M} \frac{\left(\rho_{k} / \mu_{k}\right)^{n_{k}}}{n_{k} !} & \text { if } \underline{\mathrm{n}}=\left(n_{1}, \ldots, n_{M}\right) \in \text { Feasible Region } \\ 0 & \text { otherwise }\end{array}\right.$

where $M$ is the total number of cells,

$\rho_{k}$ is the total offered traffic in cell $k$,

$1 / \mu_{k}$ is the mean dwell time in cell $k$,

$\mu_{k}=\left(1-q_{k k}\right) \mu$,

$P_{o}$ is a normalizin g constant. 


\section{Fixed Point}

- Given valu es of $\lambda_{i}$ for $i=1, \ldots, M$

- Assume initial values for $\rho_{i}$ for $i=1, \ldots, M$

- Calculate $\mathrm{p}(\underline{\rho}, \underline{\mathrm{n}})$

- Calculate $B_{i}$ for $i=1, \ldots, M$

- Calculate $v_{i j}$ for $i=1, \ldots, M$ and $j=1, \ldots, M$

- Calculate the new values for $\rho_{i}$ for $i=1, \ldots, M$ and repeat 


\section{Net Revenue $W$}

- Revenue generated by accepting a new call

- Cost of a forced termination

$$
W=\sum_{j=1}^{M}\left\{w_{j} \lambda_{j}\left(1-B_{j}\right)-c_{j}\left(\rho_{j}-\lambda_{j}\right) B_{j}\right\}
$$




\section{Implied Costs}

- Find derivative of $W$ wrt new call arrival rate

- Capture knockon effect of increases in an arrival rate

- Maximize net revenue for a given blocking probability vector 


\section{Three Cell Network}

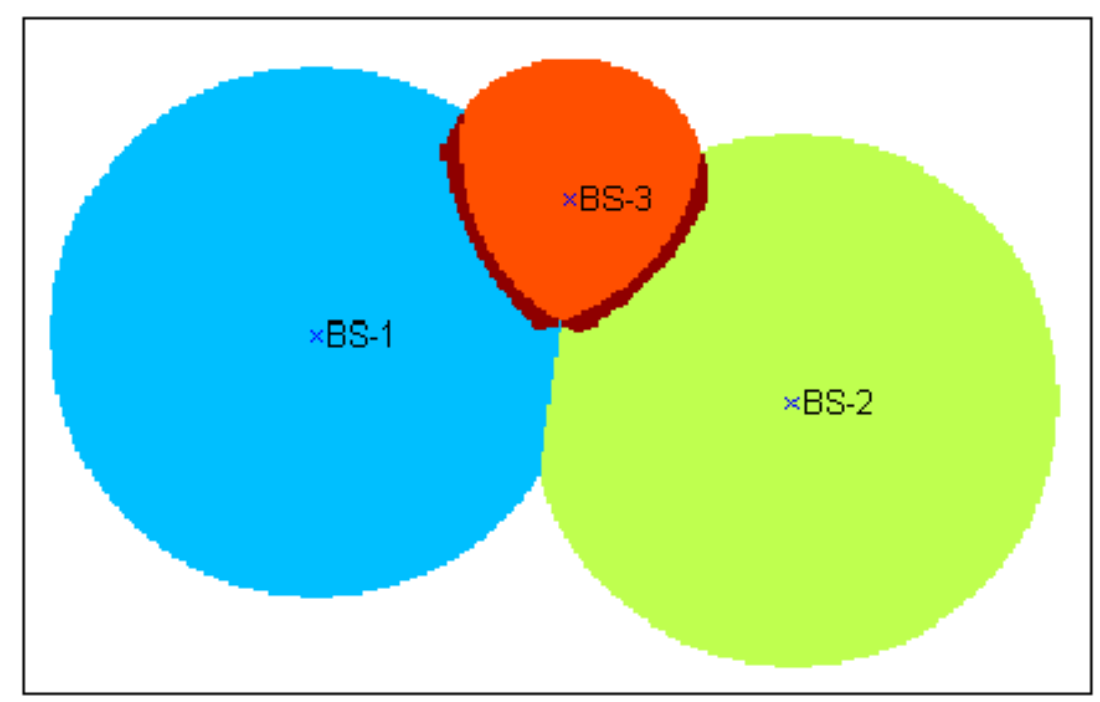

\begin{tabular}{|c|c|}
\hline & $\begin{array}{c}\text { Low } \\
\text { Mobility }\end{array}$ \\
\hline$q_{i i}$ & 0.26 \\
\hline$q_{i j}$ & 0.02 \\
\hline & $\begin{array}{c}\text { High } \\
\text { Mobility }\end{array}$ \\
\hline$q_{i i}$ & 0.00 \\
\hline$q_{i j}$ & 0.15 \\
\hline
\end{tabular}




\section{Blocking in Cell 3}

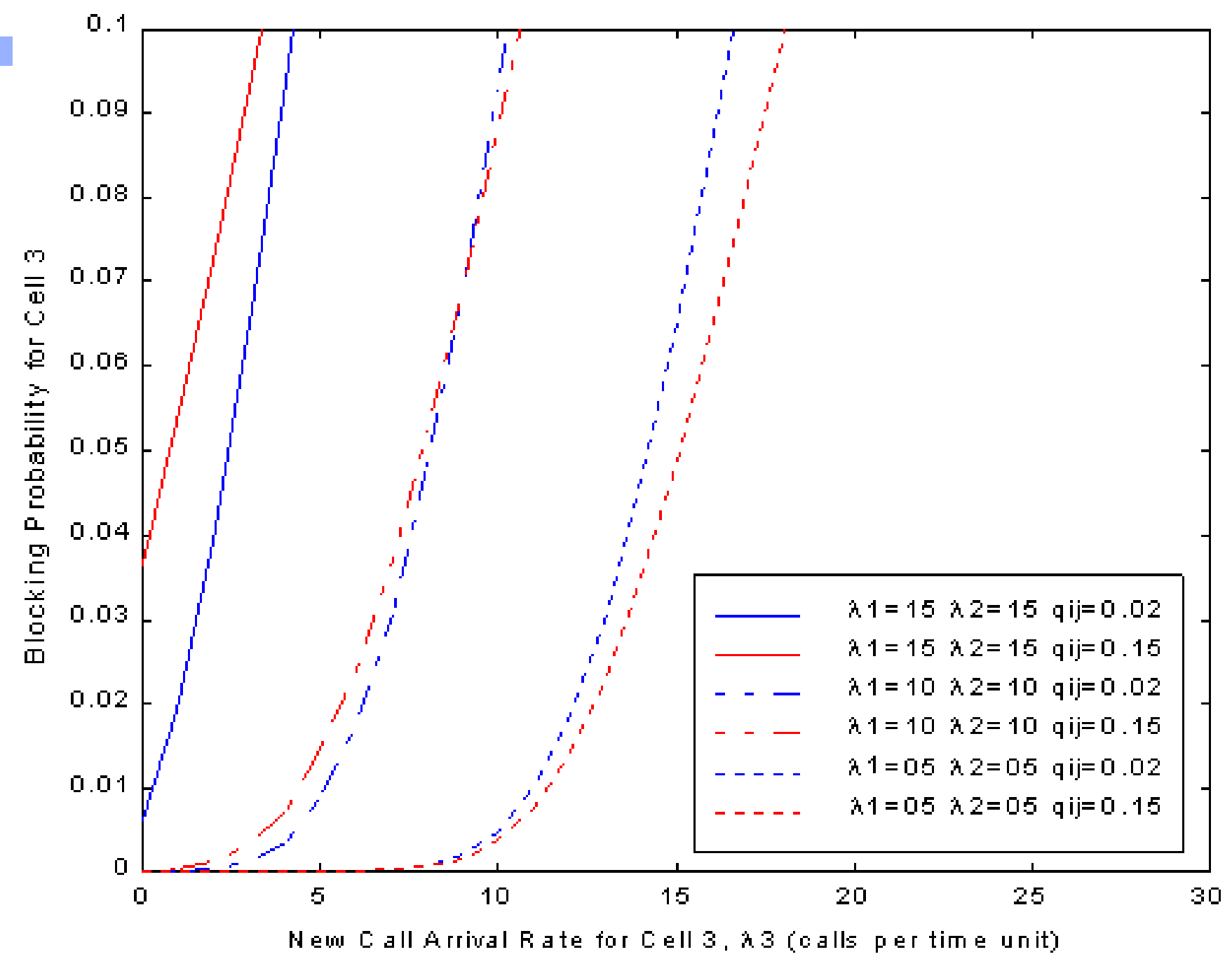




\section{Normalized Arrival Rate $\left(\rho_{3} /\left(1-q_{33}\right) u\right)$}

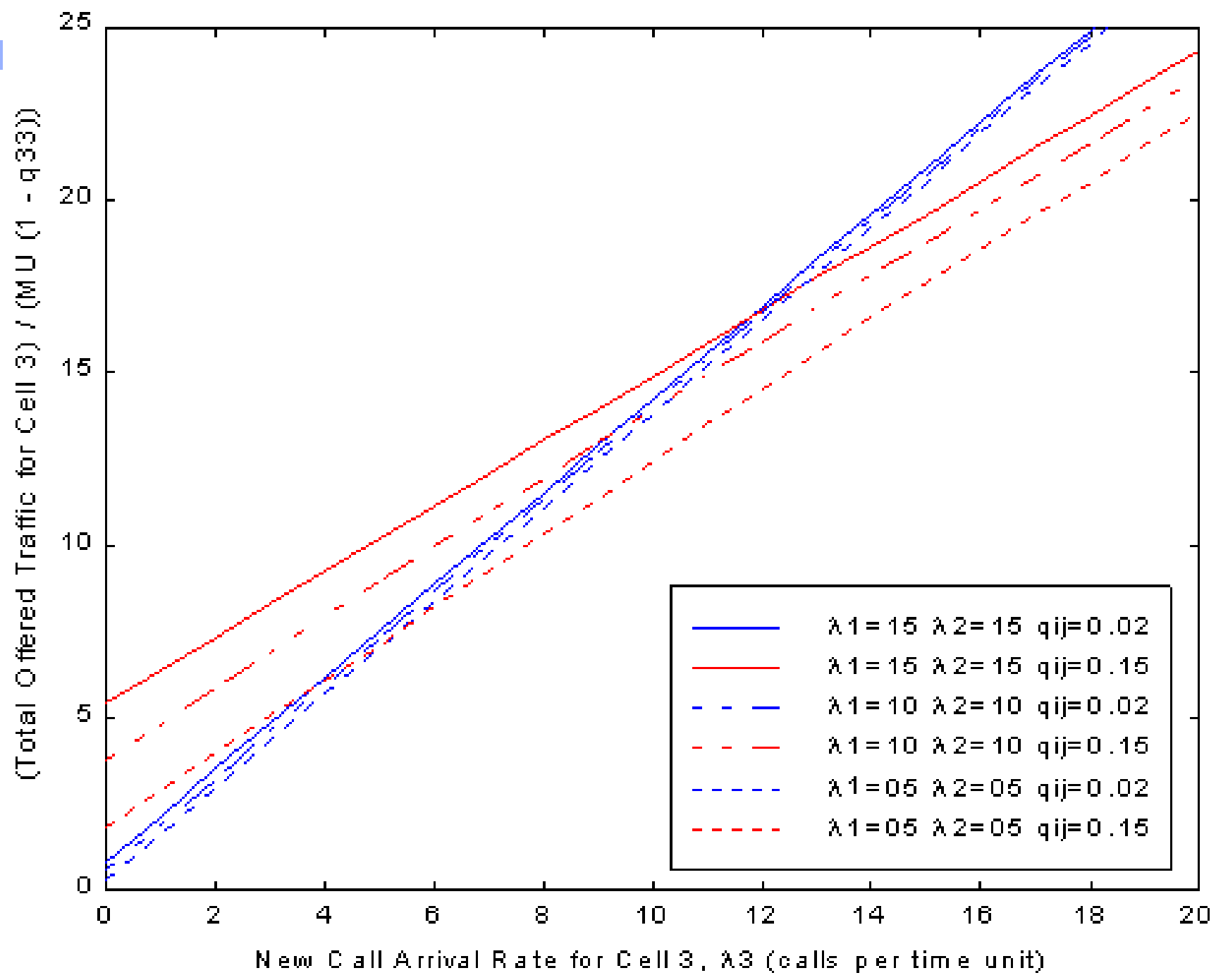




\section{Net Revenue $\mathrm{W}=1 \mathrm{C}=2$}

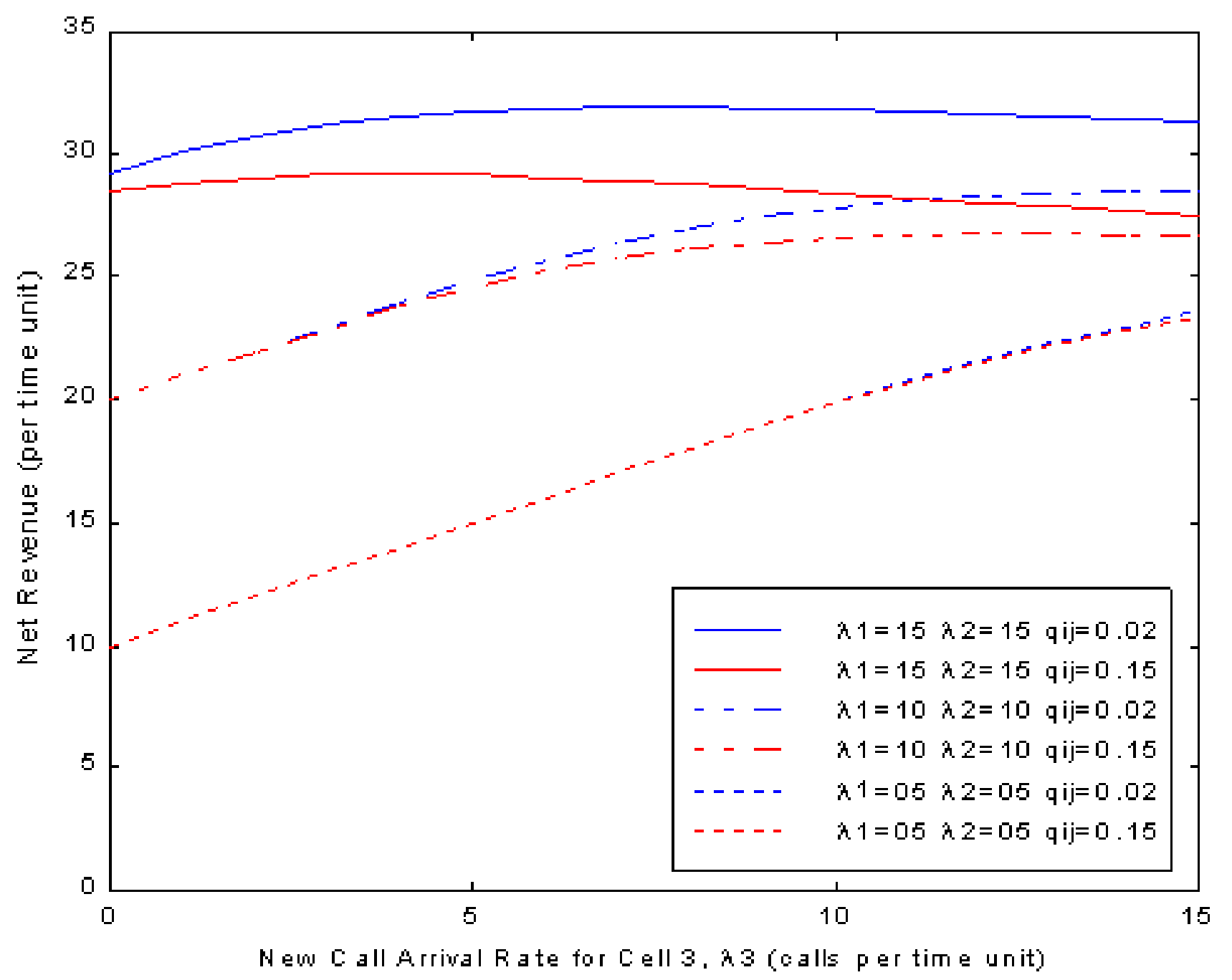




\section{Net Revenue $\mathrm{W}=1 \mathrm{C}=10$}

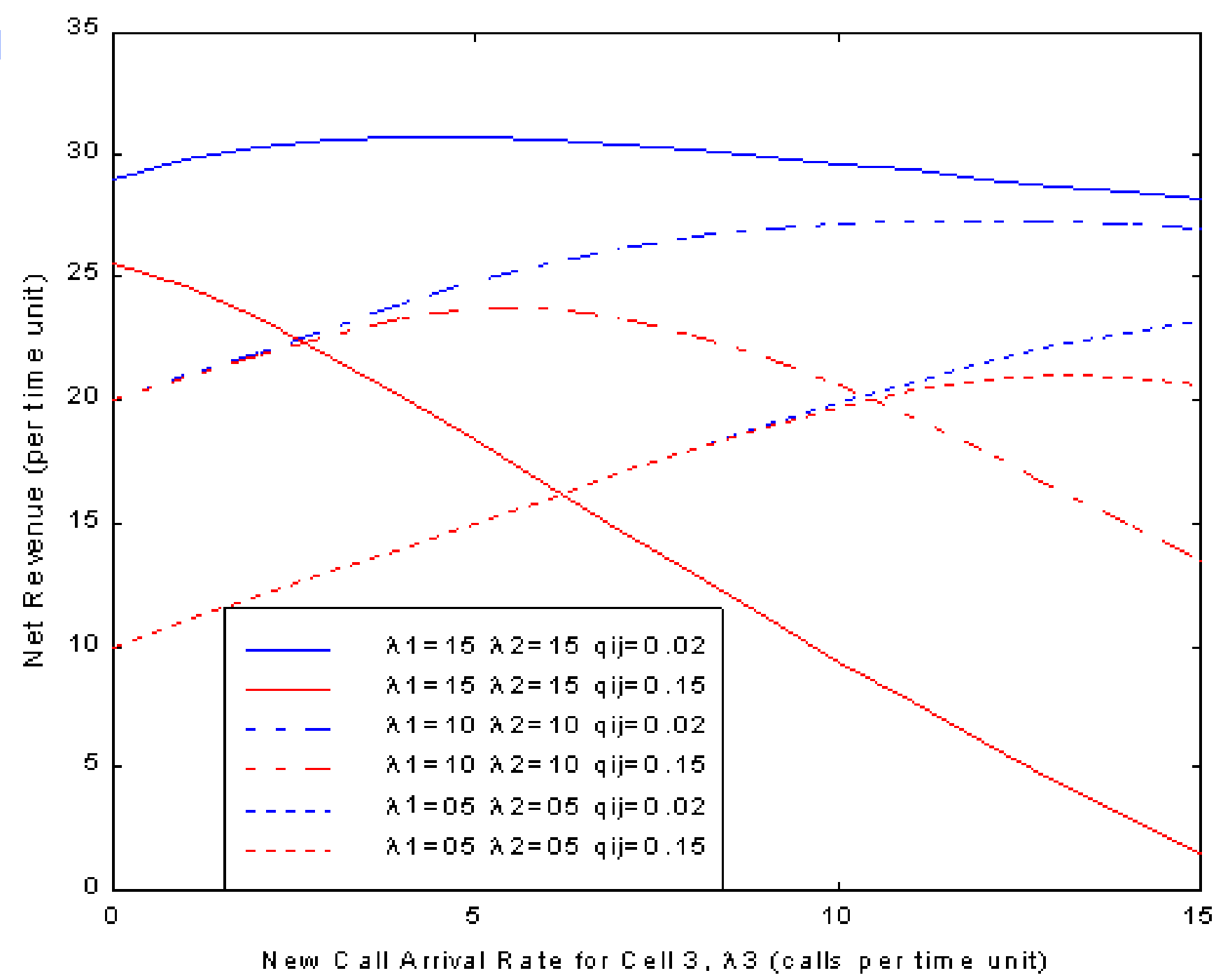




\section{Optimization of Subscribers}

- Best Scenario:

$$
\max _{\underline{\lambda}} \quad S=\sum_{i=1}^{M} \lambda_{i},
$$

$$
\begin{array}{ll}
\text { subject to } & \underline{B} \leq \underline{\eta}, \\
& \underline{\lambda} \geq \underline{0} .
\end{array}
$$

$$
\left(\text { Subscriber s }=\frac{S \text { (erlangs })}{0.025(\text { erlangs } / \mathrm{u} \mathrm{ser})}\right)
$$




\section{Optimization of Subscribers}

- Worst Scenario:

$$
\begin{array}{cl}
\max _{\underline{\lambda}} & S=\sum_{i=1}^{M} \lambda_{i}, \\
\text { subject to } & B\left(\alpha_{1}, \ldots, \alpha_{M}\right) \leq \underline{\eta} \forall \underline{\alpha} \ni \sum_{i=1}^{M} \alpha_{i} \leq S, \\
& \underline{\lambda} \geq \underline{0} .
\end{array}
$$

For all values of the arrival rates summing to $S$, the blocking probabilities do not exceed the threshold. 


\section{Maximized Subscribers}

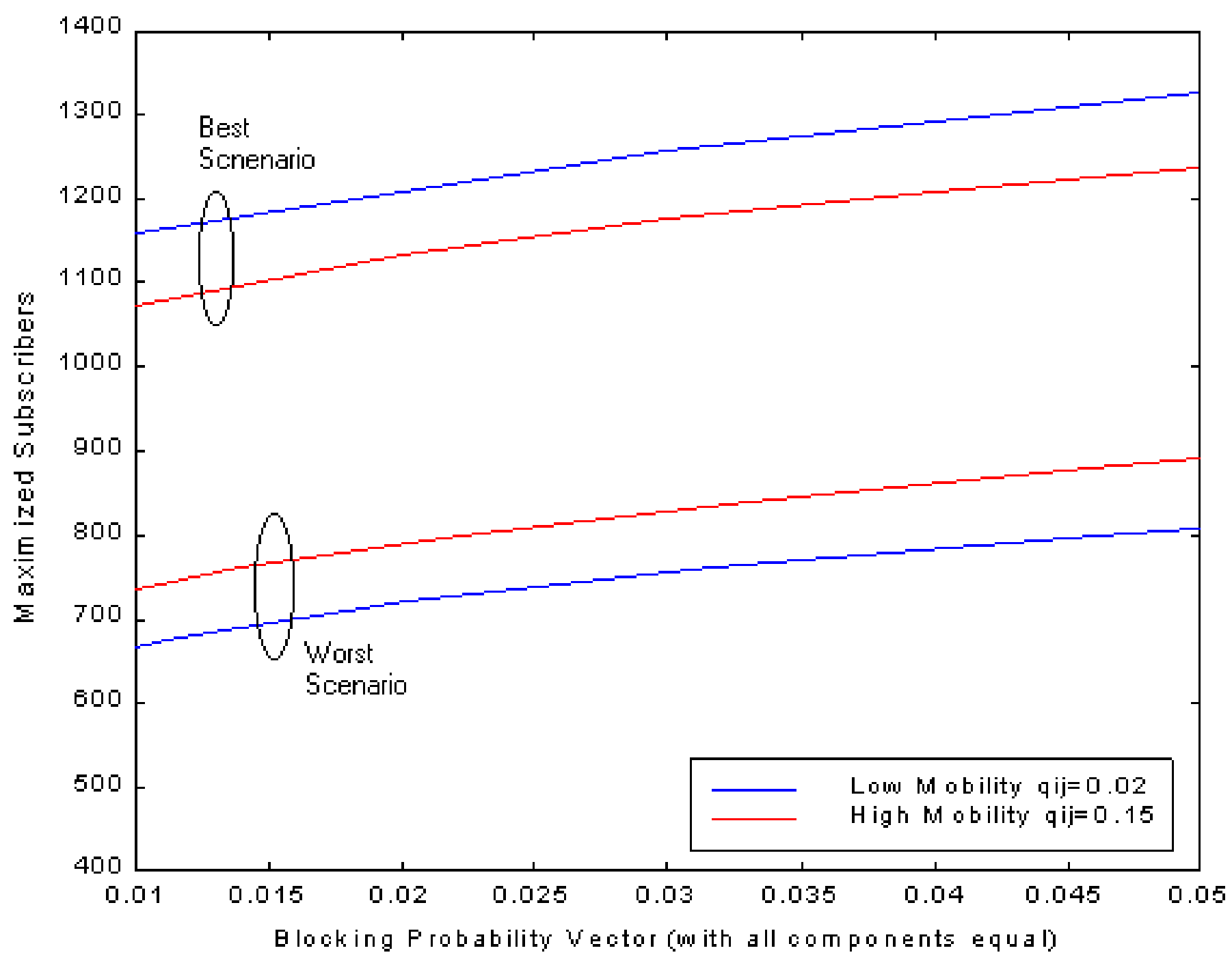




\section{Optimization of Net Revenue}

$$
\max _{\underline{\lambda}} \quad W=\sum_{j=1}^{M}\left\{w_{j} \lambda_{j}\left(1-B_{j}\right)-c_{j}\left(\rho_{j}-\lambda_{j}\right) B_{j}\right\}
$$

subject to

$$
\begin{aligned}
& \underline{B} \leq \underline{\eta}, \\
& \underline{\lambda} \geq \underline{0} .
\end{aligned}
$$




\section{Maximized Net Revenue}

$w^{\prime}{ }^{\prime}=1, c=10$

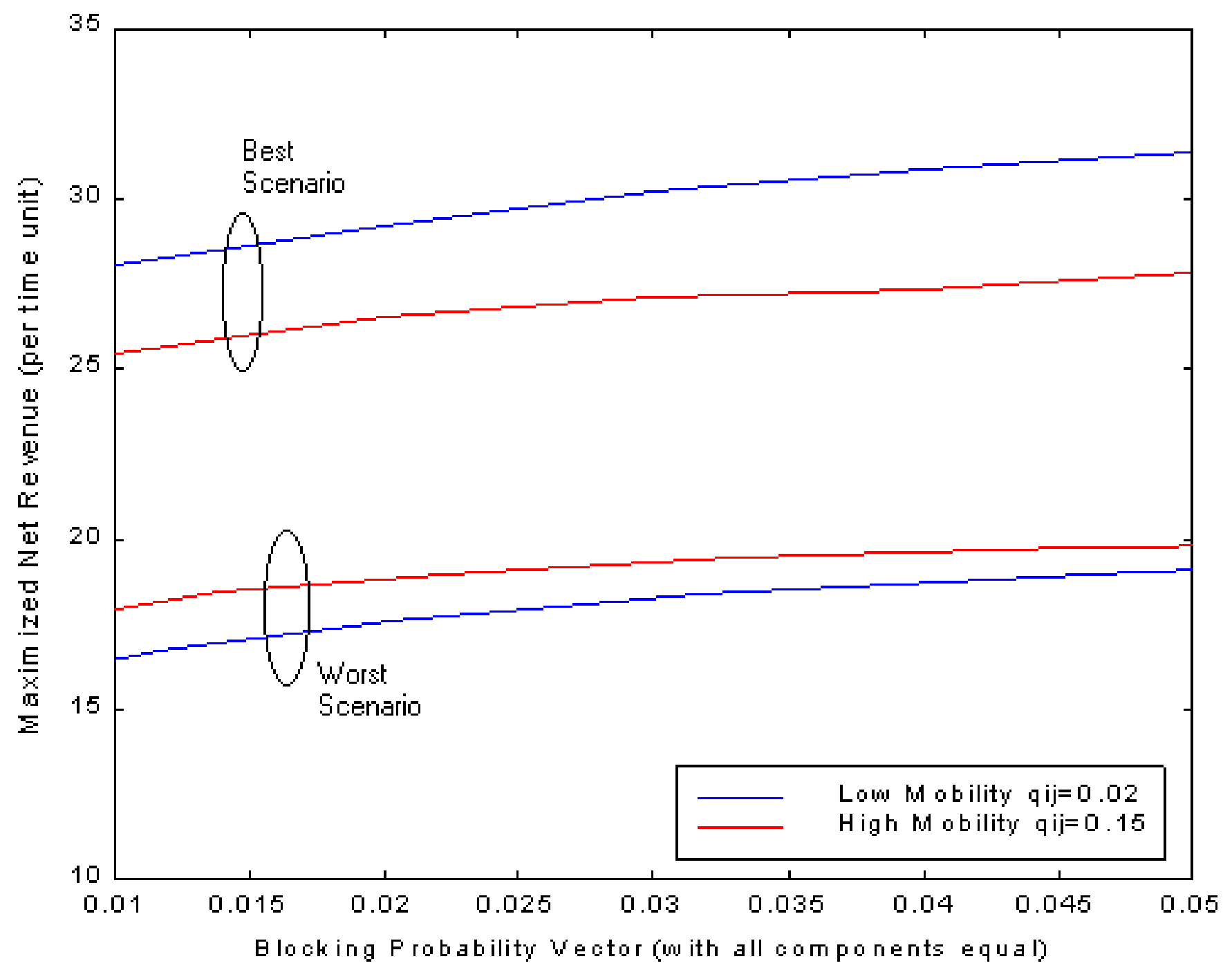




\section{Shaping Feasible Region}

- Increases capacity

- Fine tune the nominal power of the users through PCF

- PCF defined for each cell

- PCF is a design tool to maximize the capacity of the entire network 


\section{Power Compensation Factor}

- Interference is linear in PCF

$$
\begin{aligned}
& I_{j i}=\iint_{\text {cell } j} \frac{\beta_{j} r_{j}^{m} 10^{\varsigma_{j}} / 10}{r_{i}^{m} / X_{i}^{2}} \rho_{j} d A \\
& n_{i}+\sum_{j=1}^{M} n_{j} \frac{\beta_{j} \kappa_{j i}}{\beta_{i}} \leq c_{e f f} \text { for } i=1, \ldots, M .
\end{aligned}
$$

- Allows us to reshape the Feasible Region. 


\section{Equal Number of Users}

For $n_{1}=n_{2}=\ldots=n_{M}:$

$$
n_{1}=\min _{i}\left[\frac{c_{e f f}}{1+\frac{1}{\beta_{i}} \sum_{j=1}^{M} \beta_{j} \kappa_{j i}}\right] \text { for } i=1, \ldots, M .
$$

Let $i^{*}$ be the index that minimizes the above equation.

The derivative $\frac{d n_{1}}{d \beta_{k}}$ can be calculated . 


\section{Implied Cost}

$\frac{d n_{1}}{d \beta_{k}}=\frac{-c_{e f f} \beta_{i^{*}} \kappa_{k i}}{\left(\beta_{i^{*}}+\sum_{j=1}^{M} \beta_{j} \kappa_{j i}\right)^{2}}$ if $k \neq i^{*}$

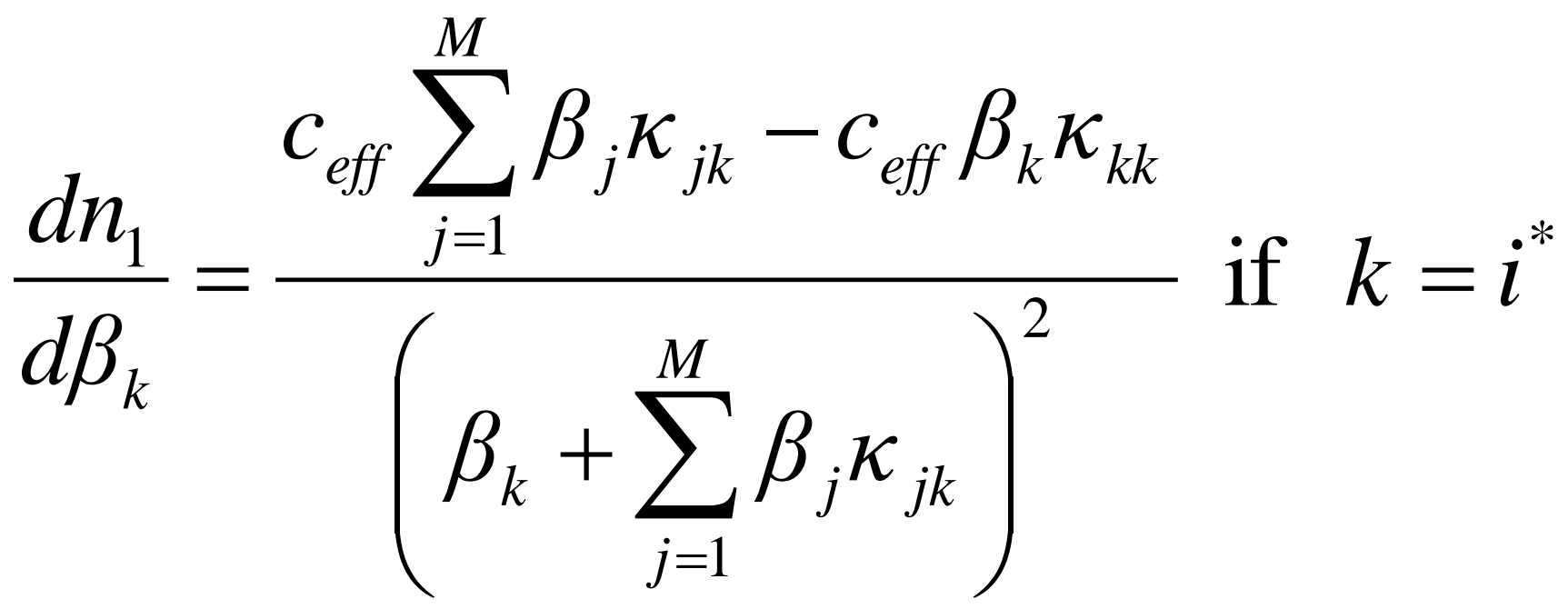




\section{Shaping with PCF}

$$
\begin{array}{cl}
\max _{\underline{\beta}, n_{1}} & M n_{1}, \\
\text { subject to } & 1 \leq \underline{\beta} \leq \underline{\beta}^{\max }, \\
& n_{1}+\sum_{j=1}^{M} n_{j} \frac{\beta_{j} \kappa_{j i}}{\beta_{i}} \leq c_{e f f}, \\
& \text { for } i=1, \ldots, M .
\end{array}
$$




\section{Two Cell Network}

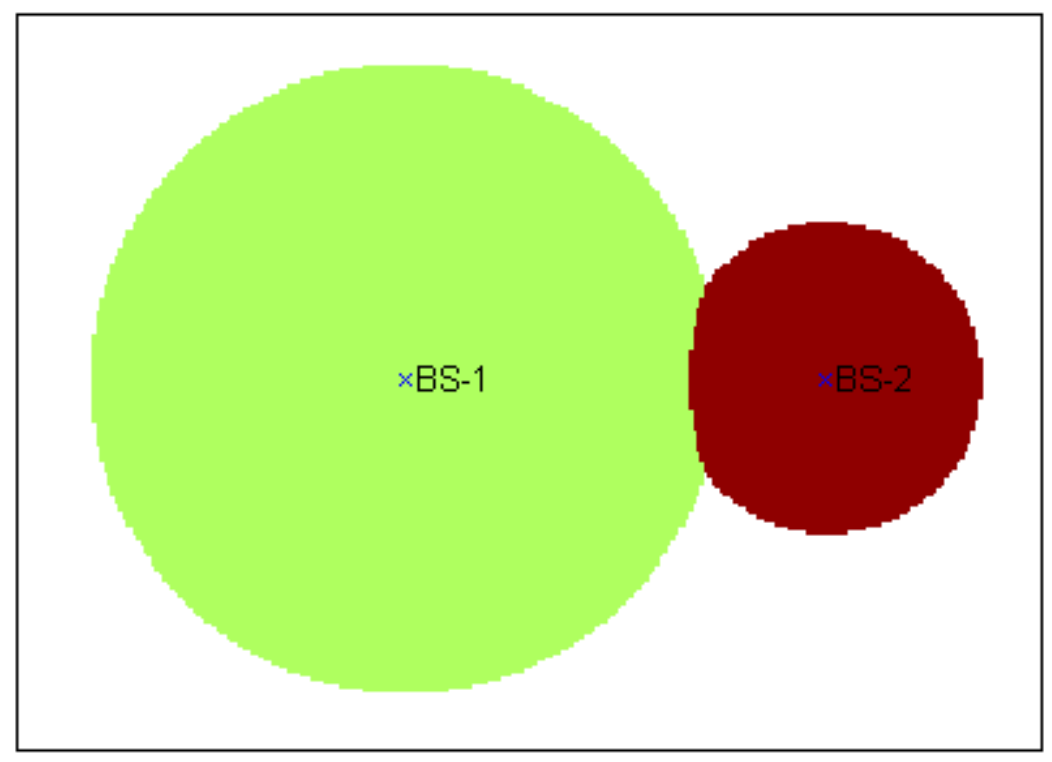

Mobility
\begin{tabular}{|l|l|}
\hline$q_{i i}$ & 0.04 \\
\hline$q_{i j}$ & 0.26 \\
\hline
\end{tabular}




\section{Feasible Region}

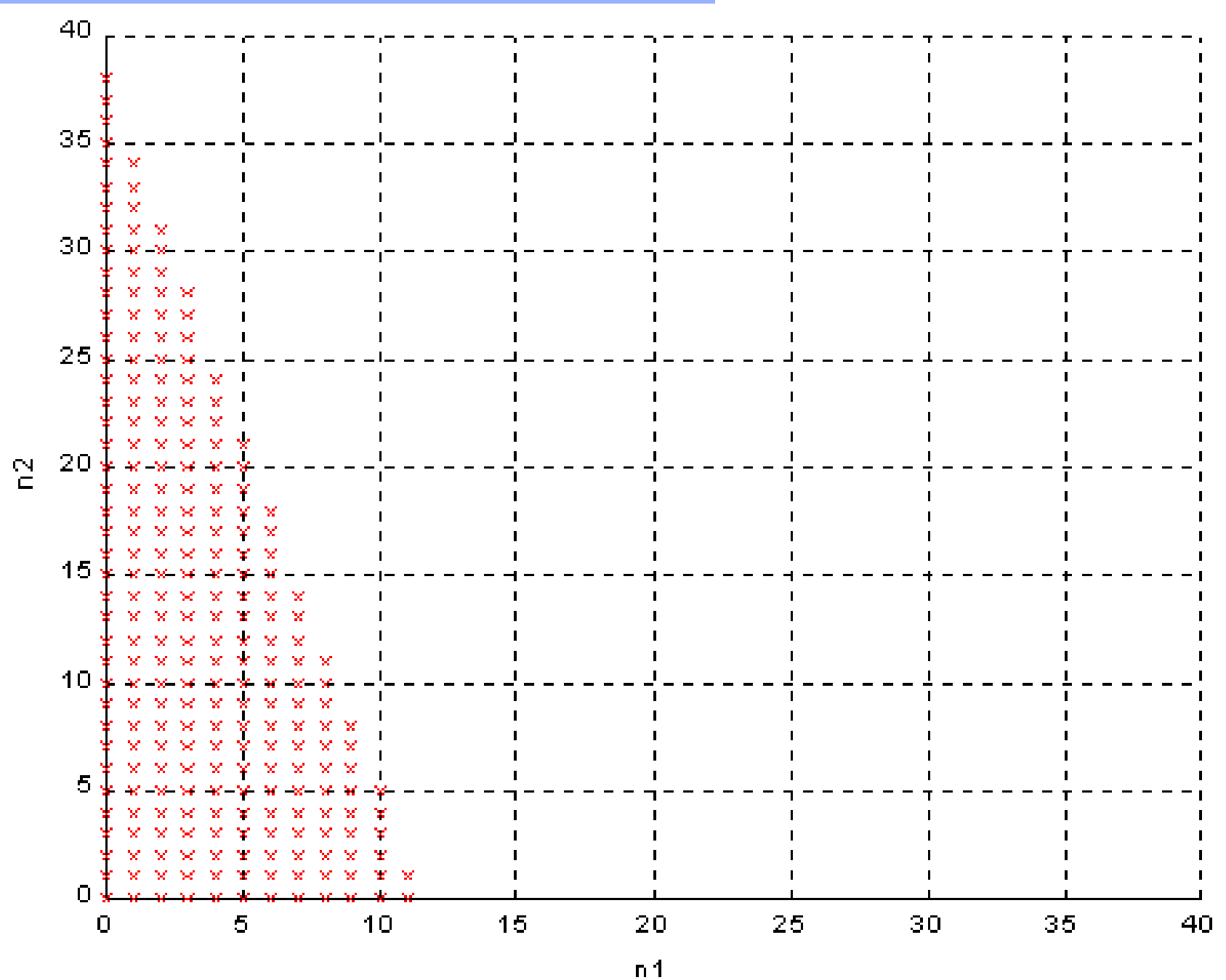




\section{Shaped Feasible Region}

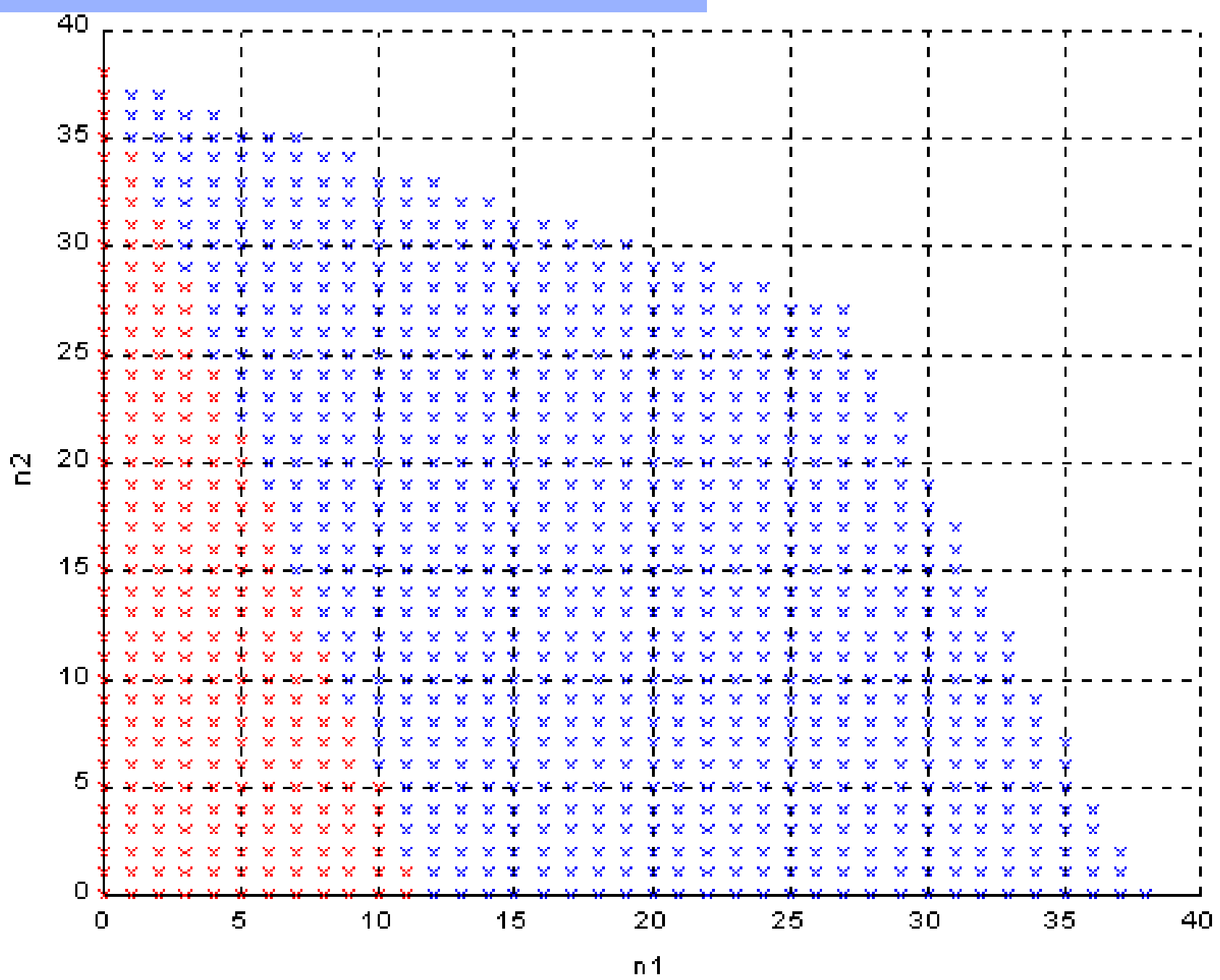




\section{Maximized Subscribers}

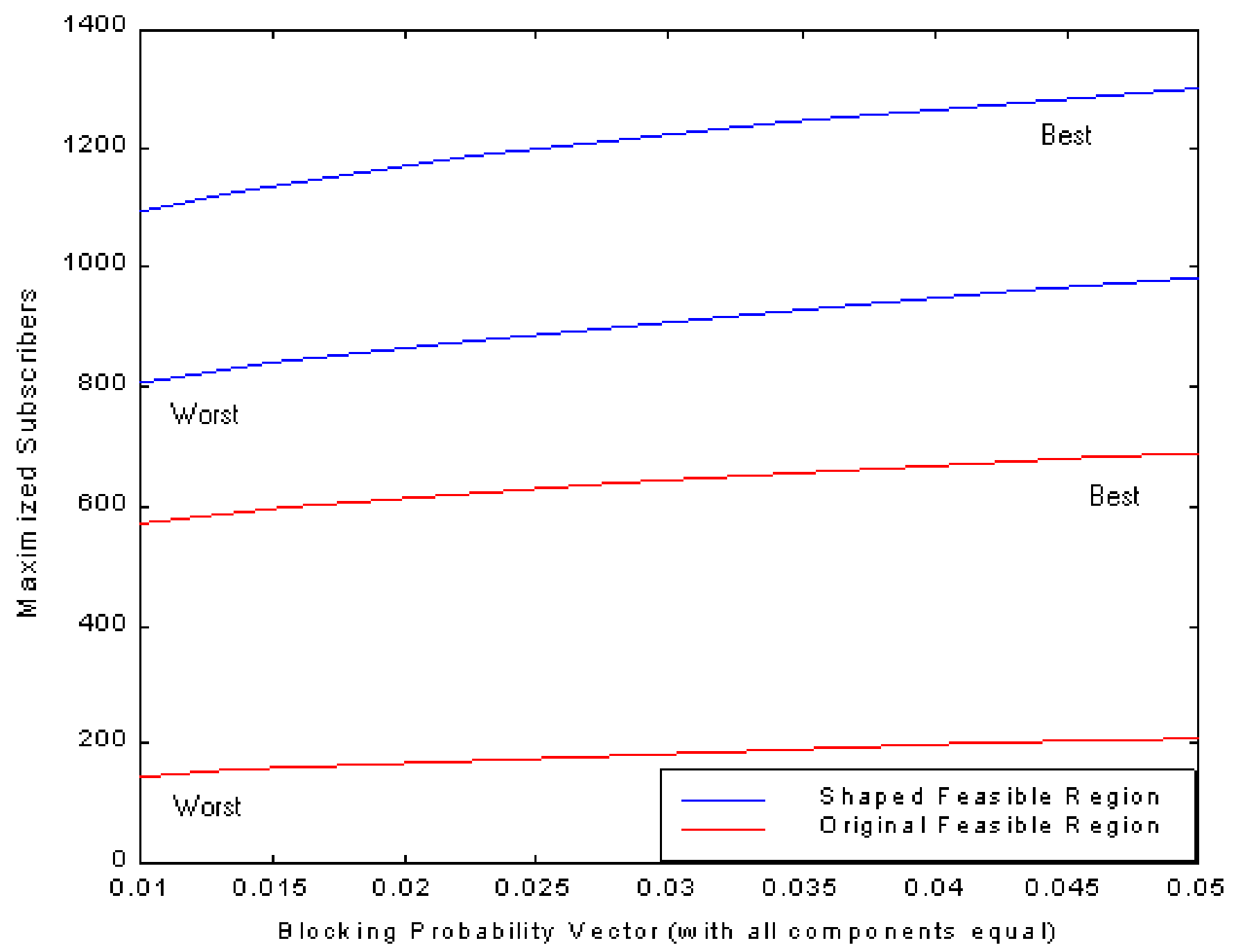




\section{Maximized Net Revenue}

$w^{\prime}=1, c=10$

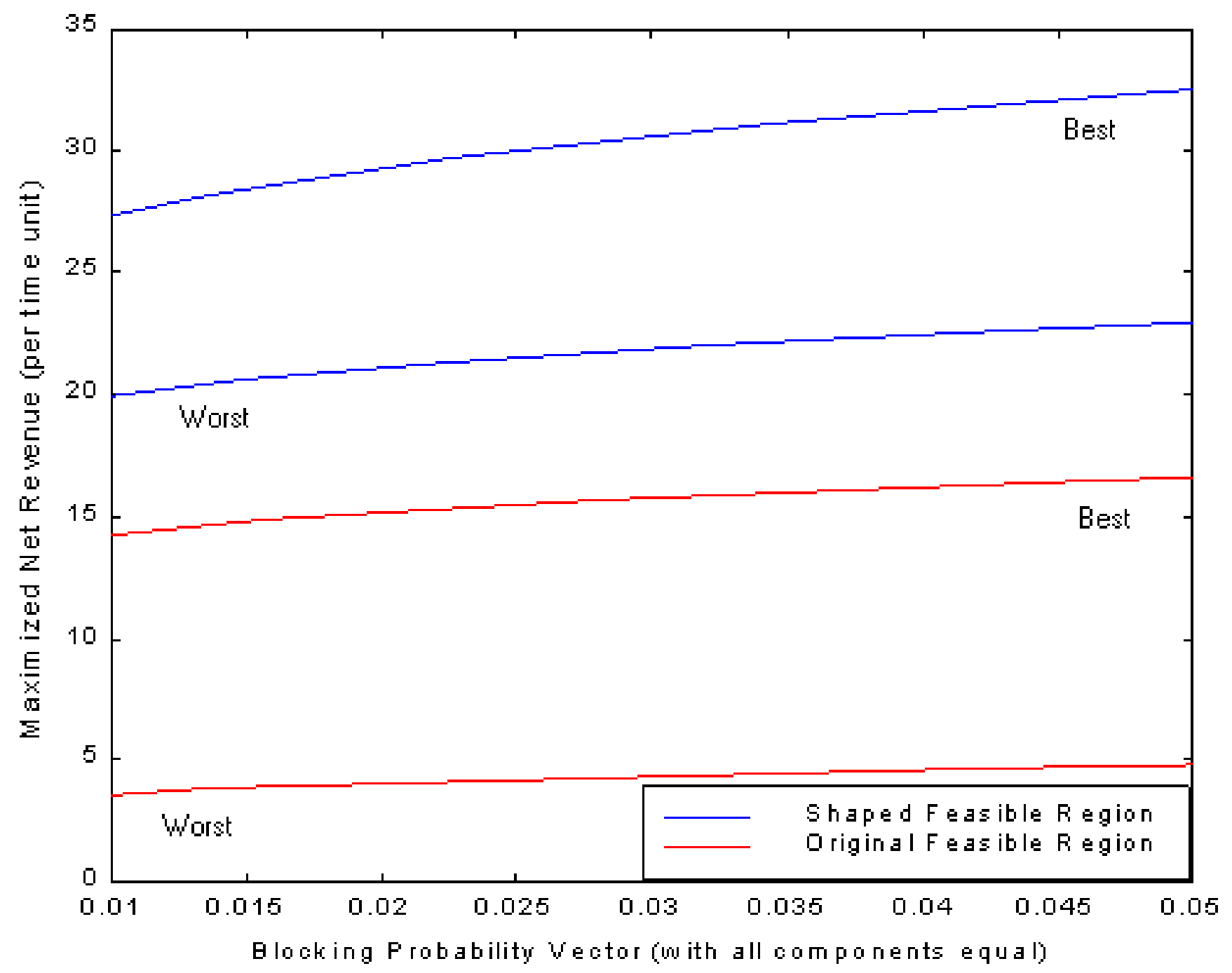




\section{Conclusions}

- For a given network topology we calculate:

- Inter-cell and intra-cell interference and Feasible Region

- Maximized net revenue

- Maximized subscriber capacity

- Effects of Mobility

- Shape feasible region to increase maximized net revenue and subscriber capacity 


\section{Future Work}

Design Problem: given a user demand distribution, what are the optimal location and coverage of Base Stations to:

- Maximize Net Revenue

- Maximize Subscriber Capacity 